\title{
Economic and clinical aspects of intravenous versus oral busulfan in adult patients for conditioning prior to HSCT
}

\author{
Karin Berger • Dorothee Schopohl • Christina Rieger • \\ Helmut Ostermann
}

Received: 29 December 2014 / Accepted: 2 March 2015 / Published online: 17 March 2015

(C) The Author(s) 2015. This article is published with open access at Springerlink.com

\begin{abstract}
Purpose Busulfan (BU) used as cytoreductive conditioning prior to hematopoietic stem cell transplantation (HSCT) is available as intravenous (IV) and oral (O) preparation. IVBU has clinical advantages associated with relevant incremental costs. The aim was to determine the economic impact of IV-BU versus O-BU in adult HSCT recipients from a German health care providers' perspective.

Methods A budget-impact model (BIM) including costs and risks for oral mucositis (OM), infection with $\mathrm{OM}$, and hepatic sinusoidal obstruction syndrome (SOS) was developed. Model inputs are literature data comparing clinical effects of IV$\mathrm{BU}$ versus $\mathrm{O}-\mathrm{BU}$ and German cost data (conditioning therapy, treatment of OM, infections, SOS without/with multiorgan failure) from literature and tariff lists.

Results Base case calculations resulted the following: total costs of adverse events were $€ 86,434$ with O-BU and $€ 44$, 376 with IV-BU for ten patients each. Considering costs of adverse events and drugs, about $€ 5840$ for ten patients receiving IV-BU are saved. Sensitivity analyses were conducted in several ways. Cost savings range between $€ 4910$ and $€ 12,640$ per ten patients for all adverse events and $€ 2070$ or $€ 1140$ per ten patients considering SOS only. Drug treatment of SOS and treatment of multiorgan failure during severe SOS are major
\end{abstract}

Karin Berger and Dorothee Schopohl contributed equally to this work.

K. Berger $\cdot$ D. Schopohl $\cdot$ C. Rieger $\cdot$ H. Ostermann Department of Haematology/Oncology, University Hospital of Munich, Marchioninistrasse 15, 81377 Munich, Germany

H. Ostermann $(\bowtie)$

Medizinische Klinik und Poliklinik III, Klinikum der Universität

München, Marchioninistrasse 15, 81377 Munich, Germany

e-mail: Helmut.Ostermann@med.uni-muenchen.de cost drivers. Worst case scenario calculations (assuming $-25 \%$ risk of all adverse events for O-BU and $+25 \%$ for IV-BU) yield up to $€ 27,570$ per ten patients with IV-BU. Conclusions Considering costs of adverse events and drugs, IV-BU is the dominant alternative from a German providers' perspective. For more comprehensive economic evaluations, additional epidemiological data, evidence on clinical outcomes, patient-reported outcomes, and treatment patterns are needed.

Keywords Busulfan · Budget-impact model · Economics · Hematopoietic stem cell transplantation · Intravenous · Oral

\section{Introduction}

European data from 2001 to 2011 for hematopoietic stem cell transplantation (HSCT) show that the number of allogeneic HSCT doubled and the number of autologous HSCT increased by $32 \%$, with an ongoing constant increase of about 1100 autologous HSCT per year since 2001 [1]. In Germany, similar increases were observed, in allogeneic HSCT $107 \%$ and in autologous HSCT $37.9 \%$ from 2001 to 2011 (first transplantations only) [2]. In the course of this development, pre-transplant regimens for both myelogenous and lymphoid malignancies are continuously refined with the aim to reduce toxicity and to improve survival [3-5]. This process resulted also in a continuous replacement of total body irradiation during conditioning therapy for HSCT by the bifunctional DNA alkylating myelotoxic agent busulfan (BU) $[4,6,5]$. The availability of the intravenous (IV) formulation of BU plays an important role in the development of optimized treatment plans $[4-6,3]$.

Oral intake of BU is problematic due to the large number of tablets, which are required to achieve recommended BU doses [7]. Oral BU intake causes severe irritation of the gastric 
mucosa accompanied by nausea and vomiting. Intestinal absorption of the drug is highly variable, and bioavailability is largely unpredictable. Wide inter- and intra-patient variability in BU pharmacokinetics is therefore a concern $[5,7]$. The therapeutic range of $\mathrm{BU}$ is narrow, and the total exposure to BU seems to be critical for graft rejection and survival $[5,6$, 3]. Oral mucositis $(\mathrm{OM})$ and its consequences like severe pain, problems of food intake, and rising risk of infection are observed more frequently with the oral preparation of BU (O$\mathrm{BU})$. The life-threatening complication of hepatic sinusoidal obstruction syndrome (SOS) is a major complication of BU. In clinical trials, it could be demonstrated that these adverse events are reduced by use of the IV formulation [8-14].

The advantageous IV formulation of BU is associated with incremental costs compared to O-BU. In Germany, an extra budget, a so-called "Zusatzentgelt" ZE 79, is paid for the use of IV-BU for HSCT recipients below the age of 15 years [15]. So far, IV-BU administration in adult patients is not covered by a "Zusatzentgelt." Additional costs associated with IV-BU have to be covered by budget reimbursed through the specific diagnosis-related groups (DRG). In 2012, 767 adult German patients, $12.3 \%$ of all $\mathrm{HSCT}$, received $\mathrm{BU}$ for conditioning prior to HSCT. Replacing O-BU with IV-BU would result in an increase of total drug costs by approximately $€ 2.5$ to $€ 3$ million. However, from an economic perspective, it might be misleading to consider isolated drug costs only. The impact of total cost in comparison to the previous standard of care has to be evaluated to determine the economic value. New therapies, which are expensive, might be adopted, because they result in essentially the same net total costs as the comparator due to a reduction in costs for the treatment of adverse events. Budgetimpact models (BIMs) can be used to calculate "the net cumulative cost of treatment with a particular therapy for a given number of patients in a specific population" [16, 17]. BIMs might give advice to the provider during decision making.

In the following, the development of a BIM is described, analyzing net cumulative costs in adult HSCT recipients from a German providers' perspective comparing the IV formulation of BU to the oral preparation.

\section{Methods}

Budget-impact model (BIM)

Model calculations are recommended to be used when the number of data regarding treatment outcomes and treatment patterns is limited. A decision tree model was developed with Microsoft Excel 2010 ${ }^{\circledR}$ to evaluate the budget impact of IV$\mathrm{BU}$ versus O-BU during conditioning for HSCT from a German health care providers' perspective. Drug costs, as well as frequency and treatment costs of drug-related side effects and adverse reactions, were considered (Fig. 1).
Model input

PubMED was searched for data comparing IV-BU versus O$\mathrm{BU}$ regarding risks for $\mathrm{OM}$, infection with $\mathrm{OM}$ and $\mathrm{SOS}$ with or without multiorgan failure (MOF). The following searches were conducted: ("Busulfan"[Mesh]) and "Administration, Intravenous"[Mesh]; ("Economics"[Mesh]) and "Stomatitis"[Mesh]; ("Hepatic Veno-Occlusive Disease"[Mesh]) and "Busulfan"[Mesh]; "Busulfan"[Mesh] review, last 10 years; "Hepatic Veno-Occlusive Disease" [Mesh] review, last 10 years. In addition, free search terms, e.g., "oral mucositis" and "intravenous busulfan" were applied. Citations of identified journal articles were searched for further relevant publications. Desktop researches were conducted. The model input consists of event rates and cost data. Event rates for the base case and a short characterization of the study populations are given in Table $1[10,11,13,14$, $18,19]$. Mild SOS was not considered. Reliable treatment cost data and event rates are lacking for mild SOS due to generally spontaneous cessation of the disease. German cost data shown in Table 2 were taken from literature [20-25] and tariff lists, except for cost of OM grade 1-2. Due to a lack of published cost data, average costs of OM grade 1-2 were determined based on resource use (time of physicians and nurses, rinsing solutions, local anesthetics, antimycotics, morphine gel) estimated by clinical experts and trained nurses.

\section{Assumption}

Due to a lack of German cost data on SOS or length of hospital stay with SOS in Germany, it was assumed that cost of SOS is represented by treatment with defibrotide as a major cost component. Defibrotide is recommended for treatment of SOS [26].

\section{Base case}

Calculations in the model were started with a base case. Adult patient weighed $70 \mathrm{~kg}$ was conditioned prior to HSCT with $1.0 \mathrm{mg} / \mathrm{kg}$ O-BU or $0.8 \mathrm{mg} / \mathrm{kg}$ IV-BU four times daily for 4 days. The event rates of OM and SOS for the base case were taken from the studies of Sobecks et al. [14] and Lee et al. [13] (Table 1). Both are more recent studies with large study populations concerning allogeneic HSCT and conditioning with BU and cyclophosphamide.

Sensitivity analyses

Sensitivity analyses were conducted in several ways. (1) Event rates of OM from the study of Ferrara et al. [10] and event rates of SOS from the study of Kashyap et al. [11] were inserted in the model (Table 3). (2) Calculations were conducted considering SOS only without costs for OM and infection 
Fig. 1 Decision tree. HSCT hematopoietic stem cell transplantation, $B U$ busulfan, $I V$ intravenous, $O$ oral, $O M$ oral mucositis, SOS hepatic sinusoidal obstruction syndrome, $M O F$ multiorgan failure

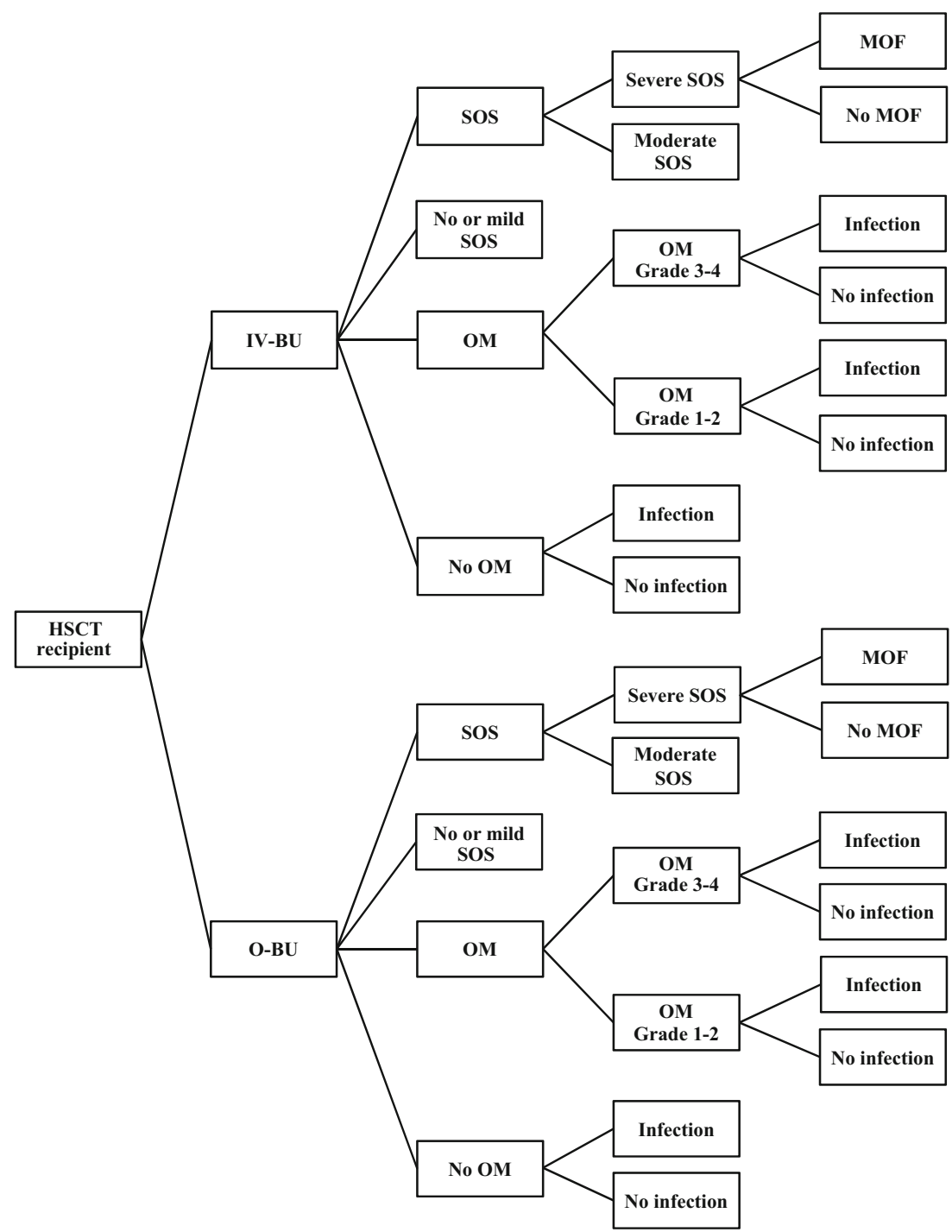

with OM. (3) Minus and plus $25 \%$ of risks of all adverse events for O-BU and IV-BU were applied. (4) A worst case scenario was calculated assuming minus $25 \%$ of risks of all adverse events for O-BU and plus $25 \%$ for IV-BU [27].

\section{Model output}

Model output was expressed as total costs of adverse events with O-BU, total costs of adverse events with IV-BU, total costs of adverse events with O-BU plus drug costs of O-BU, and total costs of adverse events with IV-BU plus drug costs of IV-BU. Results were presented as follows: cost savings or additional costs with IV-BU for ten patients; total costs for groups of ten patients receiving O-BU or IV-BU, respectively. In worst case scenarios assuming minus $25 \%$ of risks of all adverse events for O-BU and plus $25 \%$ for IV-BU, potentially arising additional costs per ten patients with IV-BU were calculated. All calculations were done using the event rates from the different studies available. All adverse events were considered, as well as drug costs for O-BU and IV-BU, if not otherwise stated.

Number needed to treat

The number needed to treat (NNT) to prevent one additional severe SOS was calculated using the base case event rates from the study of Lee et al. (Table 1) [13]. A range was given: lower border is a high hypothetical case of occurrence of SOS with ten times higher event rates; upper border is a low hypothetical case of occurrence of SOS with ten times lower event rates [28].

\section{Results}

Drug costs considering ten patients for conditioning with $\mathrm{O}-$ BU are $€ 13,160$ and with IV-BU €49,380 [25]. 
Table 1 Model input: event rates base case

\begin{tabular}{|c|c|c|c|c|}
\hline \multirow[t]{2}{*}{ Parameter } & \multicolumn{2}{|c|}{ Event rate $[\%]$} & \multirow[t]{2}{*}{ Study population } & \multirow[t]{2}{*}{ Source } \\
\hline & $\mathrm{O}-\mathrm{BU}$ & IV-BU & & \\
\hline \multicolumn{5}{|l|}{ Risk of oral mucositis (OM) } \\
\hline Patients without OM & 44.18 & 97.5 & \multirow{3}{*}{$\begin{array}{l}\text { Allogeneic HSCT; conditioning: BU/cyclophosphamide; } \\
93 \text { patients O-BU compared to } 42 \text { patients IV-BU }\end{array}$} & \multirow[t]{3}{*}{ Sobecks et al. (2012) [14] } \\
\hline Patients with OM Grade 1-2 & 31.4 & 0 & & \\
\hline Patients with OM Grade 3-4 & 24.42 & 2.5 & & \\
\hline \multicolumn{5}{|l|}{ Risk of documented infection with $\mathrm{OM}$} \\
\hline Patients with infection without $\mathrm{OM}$ & \multirow{2}{*}{\multicolumn{2}{|c|}{$\begin{array}{l}18.12 \\
18.98\end{array}$}} & \multirow{3}{*}{$\begin{array}{l}599 \text { Cancer patients with chemotherapy-induced } \\
\text { myelosuppression }\end{array}$} & \multirow[t]{3}{*}{ Elting et al. (2003) [19] } \\
\hline Patients with infection with OM Grade 1-2 & & & & \\
\hline Patients with infection with OM Grade 3-4 & \multicolumn{2}{|c|}{35.71} & & \\
\hline \multicolumn{5}{|c|}{ Risk of hepatic sinusoidal obstruction syndrome (SOS) } \\
\hline Patients with moderate SOS & 16.67 & 14.55 & \multirow{3}{*}{$\begin{array}{l}\text { Allogeneic HSCT; conditioning: BU/cyclophosphamide; } \\
186 \text { patients O-BU compared to } 55 \text { patients IV-BU }\end{array}$} & \multirow[t]{3}{*}{ Lee et al. (2005) [13] } \\
\hline Patients with severe SOS & 5.91 & & & \\
\hline Patients with severe SOS with MOF & 4.98 & 0 & & \\
\hline $\begin{array}{l}\text { Frequency to develop fatal multiorgan } \\
\text { failure (MOF) with severe SOS }\end{array}$ & \multicolumn{2}{|l|}{84.3} & $\begin{array}{l}\text { Meta-analysis of published studies from } 1979 \\
\text { to October } 2007\end{array}$ & Coppell et al. (2010) [18] \\
\hline
\end{tabular}

Results for base case calculations and sensitivity analyses are displayed in Fig. 2. All calculations ended up in cost savings with IV-BU.

Table 2 Model input: cost

\begin{tabular}{|c|c|c|}
\hline Parameter & Cost $[€]$ & Source \\
\hline \multicolumn{3}{|l|}{ Drug costs } \\
\hline O-BU $1 \mathrm{mg}$ & 1.18 & $\begin{array}{l}\text { Wholesale price } 2013 \\
\text { exclusive of VAT [25] }\end{array}$ \\
\hline IV-BU $1 \mathrm{mg}$ & 5.51 & $\begin{array}{l}\text { Wholesale price } 2013 \\
\text { exclusive of VAT [25] }\end{array}$ \\
\hline Defibrotide $1 \mathrm{mg}$ & 0.82 & $\begin{array}{l}\text { German NUB } \\
\quad \text { Antrag 2012/2013 [24] }\end{array}$ \\
\hline \multicolumn{3}{|c|}{ Total costs for adverse events } \\
\hline OM Grade 1-2 & 50 & $\begin{array}{l}\text { Own estimation based on } \\
\text { clinical experts }\end{array}$ \\
\hline OM Grade 3-4 & 312 & Banz et al.(2011) [20] \\
\hline Infection & 7093 & Paessens et al. (2011) [22] \\
\hline Moderate SOS & 21398 & a \\
\hline Severe SOS & 35663 & a \\
\hline Severe SOS with MOF & 61109 & $\mathrm{~b}$ \\
\hline
\end{tabular}

VAT value-added tax

${ }^{\text {a }}$ Costs of SOS were estimated calculating the costs of treatment with defibrotide according to the German NUB Antrag (new examination and treatment methods application) 2012/2013 assuming dosing according to Richardson et al. [23, 24]. Average duration of moderate and severe SOS (15 and 25 days, respectively) were taken from the study of Lee et al. [13]

${ }^{\mathrm{b}}$ Cost of MOF was estimated by addition of German costs for fatal sepsis to costs of severe SOS [21]
Considering SOS only as a relevant adverse event and disregarding $\mathrm{OM}$ and infection with $\mathrm{OM}$, cost savings in the model are approximately $€ 2070$ per ten patients applying the data of Lee et al. [13] and $€ 1140$ per ten patients with the data of Kashyap et al. [11].

In the base case, total costs of adverse events were $€ 86,434$ with $\mathrm{O}-\mathrm{BU}$ and $€ 44,376$ with IV-BU for ten patients each. Total costs of adverse events with O-BU plus drug costs of O-BU were $€ 99,594$ and with IV-BU plus drug costs of IV-BU $€ 93,755$ for ten patients each (Fig. 3a, base case: event rates from Sobecks/Elting/Lee et al.). Cost of adverse events plus drug costs of BU using the different study data available are shown in Fig. 3b-d. The development of total costs in sensitivity analyses assuming either minus $25 \%$ (minimum) or plus $25 \%$ (maximum) of risks of all adverse events for OBU and IV-BU for the base case and all different study data available is included in Fig. 3a-d.

Calculating worst case scenarios assuming minus $25 \%$ of risks of all adverse events for O-BU and plus $25 \%$ for IV-BU results in additional costs with IV-BU of $€ 27,570$ per ten patients with the data of Sobecks et al. [14] and Lee et al. [13] (base case), $€ 25,040$ per ten patients with the data of Sobecks et al. [14] and Kashyap et al. [11], €24,970 per ten patients with the data of Ferrara et al. [10] and Lee et al. [13], €22,440 per ten patients with the data of Ferrara et al. [10] and Kashyap et al. [11]. Omitting the costs for OM and infection with $\mathrm{OM}$ in the worst case scenario leads to additional costs with IV-BU of $€ 23,070$ per ten patients using the data of Lee et al. [13] for SOS and of $€ 22,830$ per ten patients using the data of Kashyap et al. [11] for SOS.

The average NNT results in 17 patients needed to treat to prevent one case of severe SOS, with a range of 2 to 169 
Table 3 Model input: event rates sensitivity analyses

\begin{tabular}{lccccc}
\hline & \multicolumn{2}{c}{ Event rate [\%] } & Study population & Source \\
\cline { 2 - 3 } & O-BU & IV-BU & & \\
\hline Risk of oral mucositis (OM) & & & & & \\
Patients without OM & 7 & 72 & Autologous HSCT; conditioning: BU/idarubicin; & Ferrara et al. (2009) [10] \\
Patients with OM Grade 1-2 & 13 & 16 & 30 patients O-BU compared to 25 patients IV-BU & \\
Patients with OM Grade 3-4 & 80 & 12 & & & \\
Risk of hepatic sinusoidal obstruction syndrome (SOS) & & & Kashyap et al. (2002) [11] \\
Patients with moderate SOS & 13.33 & 4.92 & Allogeneic HSCT; conditioning: BU/cyclophosphamide; & \\
Patients with severe SOS & 6.67 & 3.28 & 30 patients O-BU compared to 61 patients IV-BU & \\
Patients with severe SOS with MOF & 5.62 & 2.77 & &
\end{tabular}

patients using high and low hypothetical cases of occurrence of SOS [28].

\section{Discussion}

This is the first economic assessment of IV-BU compared to $\mathrm{O}-\mathrm{BU}$ presented for Germany. Considering risks and treatment costs for OM, infection with OM and SOS, as well as drug costs, IV-BU is cost saving and therefore dominant compared to O-BU. IV-BU remains the dominant alternative, even if the study data used for the base case are replaced by other available study data or if solely the adverse event SOS is considered.

Two other economic models have been presented so far as conference abstracts comparing costs arising with O-BU compared to IV-BU taking only SOS into consideration. Based on US costs for SOS [29], a French model calculated additional costs of $€ 1605.4$ per patient with IV-BU [30]. A costeffectiveness analysis from Mexico demonstrated that IVBU was dominant over O-BU [31]. Taking different event rates and different health care systems into consideration, a comparison with these studies is limited.

In sensitivity analyses, changes in total cost of adverse events calculating with plus and minus $25 \%$ of all risks were chosen for the following reasons: the historical nature of the available study data leads to considerable uncertainties despite a similar trend regarding the favorable results with IV-BU. The cost components could not be based on up-to-date data of treatment patterns and resource use and were estimated in a most conservative way, e.g., not including costs of hospital stay for SOS. Therefore, it did not seem adequate to analyze the influence of individual parameters in this context of uncertainties of event rates and cost components. Worst case scenarios assuming minimal risks of adverse events for OBU $(-25 \%)$ and maximal risks of adverse events for IV-BU $(+25 \%)$ result in additional costs for IV-BU amounting to a maximum of $56 \%$ of the drug costs using base case data. These extra costs appear relatively modest in the context of HSCT [32].

The average NNT with IV-BU is 17 patients to prevent one case of severe SOS. Regarding the total number of patients
Fig. 2 Average cost savings per ten patients with IV-BU. Average cost savings per ten patients with IV-BU are shown for the base case. For the sensitivity analyses, event rates of OM from the study of Ferrara et al. [10] and event rates of SOS from the study of Kashyap et al. [11] were inserted in the model. $\mathrm{S}=$ Sobecks et al. [14], E = Elting et al. [19], $\mathrm{L}=$ Lee et al. [13], $\mathrm{K}=$ Kashyap et al. [11], $\mathrm{F}=$ Ferrara et al. [10]

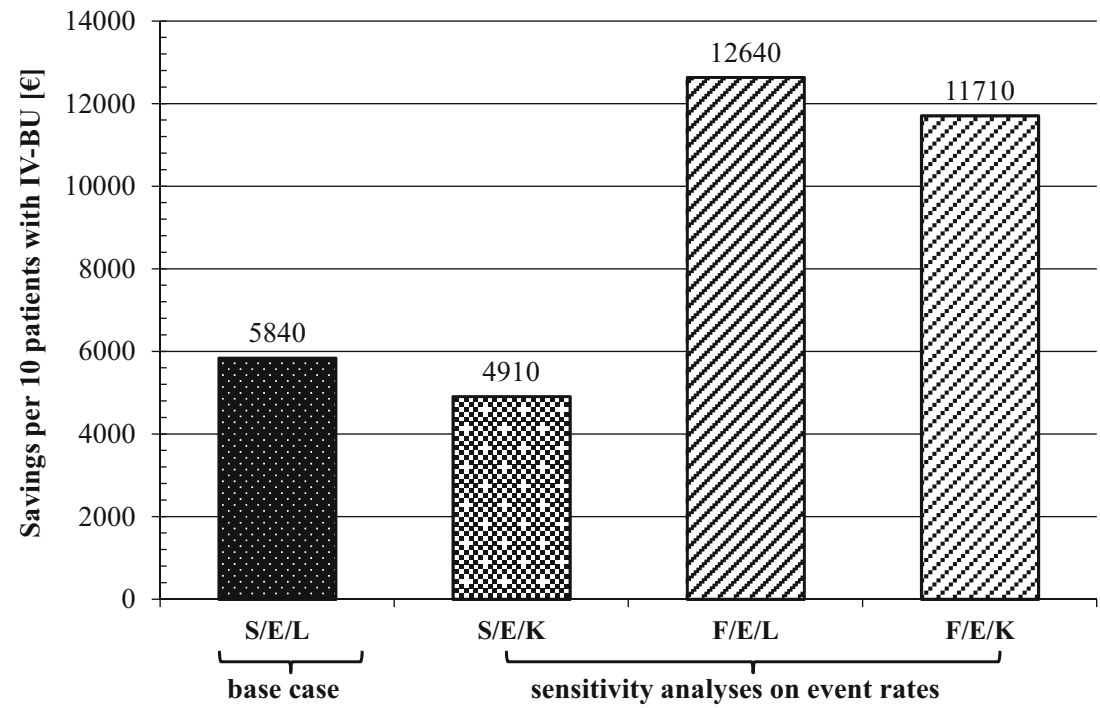


Fig. 3 Sensitivity analyses: minus and plus $25 \%$ of risks of all adverse events for O-BU and IVBU. Total costs of adverse events plus drug cost of BU are shown for groups of ten patients each with either O-BU or IV-BU. Minus $25 \%$ (minimum) and plus $25 \%$ (maximum) of risks of all adverse events for O-BU and IVBU were applied on the event rates of all available studies on $\mathrm{OM}$, infection with OM, and SOS $[10,11,13,14,19] . \mathrm{S}=$ Sobecks et al. [14], E = Elting et al. [19], $\mathrm{L}=$ Lee et al. [13], $\mathrm{K}=$ Kashyap et al. [11], $\mathrm{F}=$ Ferrara et al. [10], $(\min )=$ minimum, $(\max )=$ maximum
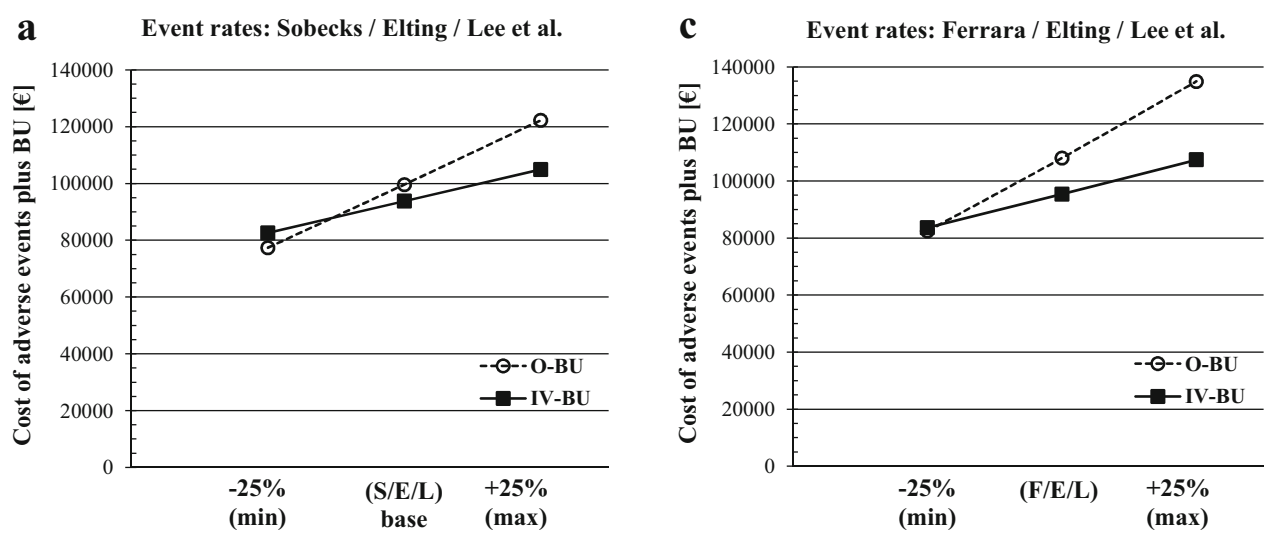

b

b Event rates: Sobecks / Elting / Kashyap et al.

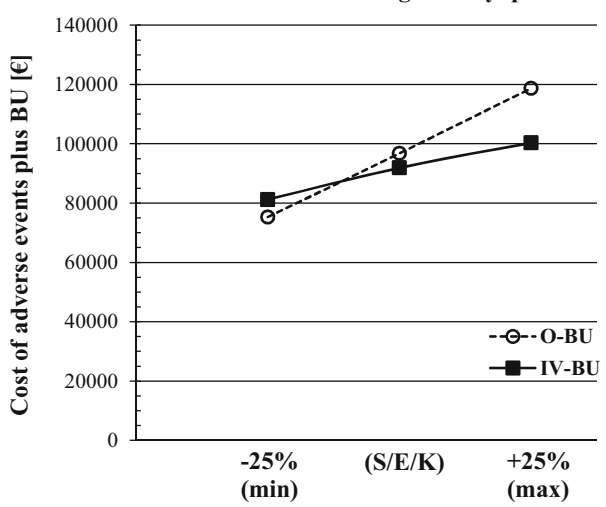

d Event rates: Ferrara / Elting / Kashyap et al.

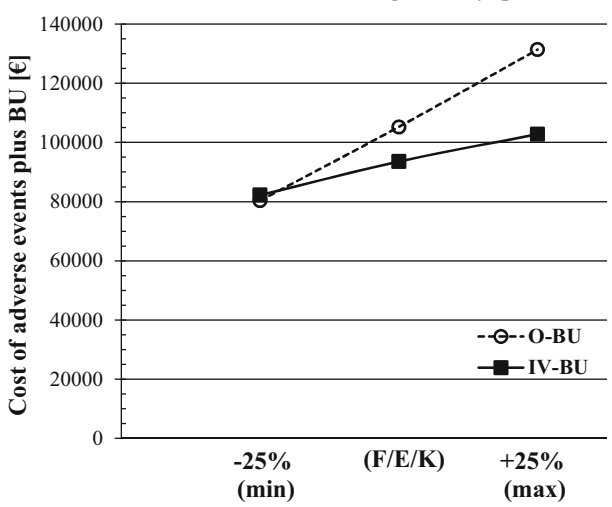

treated in Germany with BU for conditioning prior to HSCT, potentially up to 45 patients are spared severe SOS. In view of the considerable mortality of severe SOS after allogeneic HSCT, IV-BU appears highly favorable [18].

If pharmacokinetic-directed high-dose BU is used, similar results can be achieved with O-BU and IV-BU. However, the data indicated a slightly improved 5-year overall survival with IV-BU compared to O-BU [33]. A prospective cohort study comparing IV-BU with total body irradiation (TBI) used for conditioning prior to HSCT demonstrated non-inferiority of IV-BU. Two-year probabilities of survival were improved with IV-BU compared to TBI [4]. An earlier study comparing O-BU with IV-BU during reduced intensity conditioning for allogeneic HSCT found lower incidence of acute graft-versushost disease (GvHD) and early infectious complications leading to significantly improved overall survival with IV-BU [34]. Further studies are required to understand the mechanisms by which IV-BU-based regimens result in superior survival outcomes and to evaluate possible influences on GvHD. Due to increasing rates of GvHD with increasing toxicity of the regimens preceding allogeneic HSCT, the advantages of IV-BU may be even more pronounced [35]. In contrast to a cost-effectiveness analysis, a BIM does not consider differences in mortality rates of therapies, i.e., differences in life years gained [32]. Improvements in quality of life, which are achieved by less and less severe OM during treatment with IV$\mathrm{BU}$ compared to $\mathrm{O}-\mathrm{BU}$, are not reflected in the calculations.

There are some limitations concerning studies and cost data inserted in the model. The data used for the model comparing frequencies of adverse events with O-BU and IV-BU were from four retrospective clinical studies [11, 13, 14, 19] and one prospective and retrospective comparison [10] with obviously heterogenous patient populations. In one study, the groups had variable use of methotrexate [14]; in another study, patients with a different ethnic background as compared to German patients were investigated [13], and another study comprised autologous HSCT instead of allogeneic HSCT and used an experimental drug combination of BU and idarubicin [10]. The conclusions of the model had to be based exclusively on literature historical data due to lack of up-todate evidence-based studies. Infection rates with $\mathrm{OM}$ were derived from a study on chemotherapy-induced OM in cancer patients, because comparative data on infections in patients with or without OM after HSCT were not available [19]. Cost data for treatment of OM grade 3-4 and for treatment of infection were both from publications on cancer patients receiving chemotherapy [20, 22]. Published data on treatment costs of OM and infection of patients after allogeneic HSCT were not available and might differ in patients after chemotherapy due to potentially different severity and duration or different 
influence on length of hospital stay or readmission to the hospital. Estimations had also to be made for German cost data on SOS. Treatment costs of SOS were based on the assumption that defibrotide is a major cost component. This is a simplification of a probably much more complex issue. However again, German cost data on SOS or length of hospital stay with SOS in Germany were not available. Therefore, this estimation close to current clinical practice was chosen. Various approaches in the sensitivity analyses were used to account for these uncertainties. The applicability of this economic assessment of IV-BU compared to O-BU from a German providers' perspective to other countries is limited. The influence of IV$\mathrm{BU}$ on costs may produce variable results as a function of differences in treatment patterns, costs, health care systems, and the country-specific type of health economic evaluation. However, the basic approach of our model calculations can be transferred to other countries using country-specific costs for treatment of adverse events and, if available, up-to-date study data comparing IV-BU with O-BU.

\section{Conclusions}

The presented budget-impact calculations (IV-BU compared to O-BU) from a German health care providers' perspective show cost savings in overall costs of HSCT. Sensitivity analyses result in moderate cost increase for IV-BU when calculating worst case scenarios. Based on model calculations, the use of IV-BU in adult patients undergoing HSCT seems to be reasonable. Contemporary real-life data on frequencies of OM and SOS in the course of HSCT with IV-BU compared to O-BU, up-to-date treatment patterns for OM and SOS, as well as resource use and costs of OM, SOS, and HSCT are needed to allow for further analyses.

\section{Acknowledgments We thank Pierre Fabre Pharma Germany for the research support.}

Conflict of interest Prof. Ostermann, senior author, received funding from Pierre Fabre Pharma Germany. The other authors have no financial conflicts of interest to disclose and have full control of all primary data. The authors agree to allow the journal to review the data if requested.

Open Access This article is distributed under the terms of the Creative Commons Attribution Noncommercial License which permits any noncommercial use, distribution, and reproduction in any medium, provided the original author(s) and the source are credited.

\section{References}

1. Passweg JR, Baldomero H, Bregni M, Cesaro S, Dreger P, Duarte RF, Falkenburg JH, Kroger N, Farge-Bancel D, Gaspar HB, Marsh J, Mohty M, Peters C, Sureda A, Velardi A, Ruiz de Elvira C, Madrigal A (2013) Hematopoietic SCT in Europe: data and trends in 2011. Bone Marrow Transplant 48(9):1161-1167. doi:10.1038/ bmt.2013.51
2. Jahresbericht (2012) DRST Deutsches Register für Stammzelltransplantationen. http://www.drstde/download/ jb2012pdf. Accessed 01 Mar 2014

3. Parmar S, Rondon G, de Lima M, Thall P, Bassett R, Anderlini P, Kebriaei P, Khouri I, Ganesan P, Champlin R, Giralt S (2013) Dose intensification of busulfan in the preparative regimen is associated with improved survival: a phase I/II controlled, randomized study. Biol Blood Marrow Transplant 19(3):474-480. doi:10.1016/j.bbmt.2012.12.001

4. Bredeson C, LeRademacher J, Kato K, Dipersio JF, Agura E, Devine SM, Appelbaum FR, Tomblyn MR, Laport GG, Zhu X, McCarthy PL, Ho VT, Cooke KR, Armstrong E, Smith A, Rizzo JD, Burkart JM, Pasquini MC (2013) Prospective cohort study comparing intravenous busulfan to total body irradiation in hematopoietic cell transplantation. Blood 122(24):3871-3878. doi:10.1182/blood-2013-08-519009

5. Ciurea SO, Andersson BS (2009) Busulfan in hematopoietic stem cell transplantation. Biol Blood Marrow Transplant 15(5):523-536. doi:10.1016/j.bbmt.2008.12.489

6. Copelan EA, Hamilton BK, Avalos B, Ahn KW, Bolwell BJ, Zhu X, Aljurf M, van Besien K, Bredeson C, Cahn JY, Costa LJ, de Lima M, Gale RP, Hale GA, Halter J, Hamadani M, Inamoto Y, Kamble RT, Litzow MR, Loren AW, Marks DI, Olavarria E, Roy V, Sabloff M, Savani BN, Seftel M, Schouten HC, Ustun C, Waller EK, Weisdorf DJ, Wirk B, Horowitz MM, Arora M, Szer J, Cortes J, Kalaycio ME, Maziarz RT, Saber W (2013) Better leukemia-free and overall survival in AML in first remission following cyclophosphamide in combination with busulfan compared with TBI. Blood 122(24):38633870. doi:10.1182/blood-2013-07-514448

7. Nath CE, Shaw PJ (2007) Busulphan in blood and marrow transplantation: dose, route, frequency and role of therapeutic drug monitoring. Curr Clin Pharmacol 2(1):75-91

8. Aggarwal C, Gupta S, Vaughan WP, Saylors GB, Salzman DE, Katz RO, Nance AG, Tilden AB, Carabasi MH (2006) Improved outcomes in intermediate- and high-risk aggressive non-Hodgkin lymphoma after autologous hematopoietic stem cell transplantation substituting intravenous for oral busulfan in a busulfan, cyclophosphamide, and etoposide preparative regimen. Biol Blood Marrow Transplant 12(7):770-777. doi:10.1016/j.bbmt.2006.03.016

9. Dean RM, Pohlman B, Sweetenham JW, Sobecks RM, Kalaycio ME, Smith SD, Copelan EA, Andresen S, Rybicki LA, Curtis J, Bolwell BJ (2010) Superior survival after replacing oral with intravenous busulfan in autologous stem cell transplantation for non-Hodgkin lymphoma with busulfan, cyclophosphamide and etoposide. Br J Haematol 148(2):226-234. doi:10.1111/j.1365-2141.2009.07940.x

10. Ferrara F, Mele G, Palmieri S, Pedata M, Copia C, Riccardi C, Izzo T, Criscuolo C, Musto P (2009) Continuous infusion idarubicin and intravenous busulphan as conditioning regimen to autologous stem cell transplantation for patients with acute myeloid leukaemia. Hematol Oncol 27(4):198-202. doi:10.1002/hon.903

11. Kashyap A, Wingard J, Cagnoni P, Roy J, Tarantolo S, Hu W, Blume K, Niland J, Palmer JM, Vaughan W, Fernandez H, Champlin R, Forman S, Andersson BS (2002) Intravenous versus oral busulfan as part of a busulfan/cyclophosphamide preparative regimen for allogeneic hematopoietic stem cell transplantation: decreased incidence of hepatic venoocclusive disease (HVOD), HVOD-related mortality, and overall 100-day mortality. Biol Blood Marrow Transplant 8(9):493-500

12. Kim SE, Lee JH, Choi SJ, Ryu SG, Lee KH (2005) Morbidity and non-relapse mortality after allogeneic bone marrow transplantation in adult leukemia patients conditioned with busulfan plus cyclophosphamide: a retrospective comparison of oral versus intravenous busulfan. Haematologica 90(2):285-286

13. Lee JH, Choi SJ, Kim SE, Park CJ, Chi HS, Lee MS, Lee JS, Kim WK, Lee KH (2005) Decreased incidence of hepatic veno-occlusive disease and fewer hemostatic derangements associated with intravenous busulfan vs oral busulfan in adults conditioned with busulfan+ cyclophosphamide for allogeneic bone marrow transplantation. Ann Hematol 84(5):321-330. doi:10.1007/s00277-004-0982-4 
14. Sobecks RM, Rybicki L, Yurch M, Kalaycio M, Dean R, Andresen S, Pohlman B, Duong H, Bolwell B, Copelan E (2012) Intravenous compared with oral busulfan as preparation for allogeneic hematopoietic progenitor cell transplantation for AML and MDS. Bone Marrow Transplant 47(5):633-638. doi:10.1038/bmt.2011.167

15. InEK Institut für das Entgeltsystem im Krankenhaus GmbH, GDRG-Fallpauschalen-Katalog 2014. http://www.g-drgde/cms/GDRG-System 2014/Fallpauschalen-Katalog/FallpauschalenKatalog_2014. Accessed 29 Jan 2014

16. Timothy W, Smith BA, Jonothan C, Tierce C Designing and developing budget impact models suited for global adaption (summary of a workshop given at the ISPOR 10th Annual International Meeting, May 16, 2005, Washington DC, USA). http://www.ispororg/news/ articles/aug06/designingasp. Accessed 27 Jan 2014

17. Mauskopf JA, Sullivan SD, Annemans L, Caro J, Mullins CD, Nuijten M, Orlewska E, Watkins J, Trueman P (2007) Principles of good practice for budget impact analysis: report of the ISPOR Task Force on good research practices - budget impact analysis. Value Health 10(5):336-347. doi:10.1111/j.1524-4733.2007.00187.x

18. Coppell JA, Richardson PG, Soiffer R, Martin PL, Kernan NA, Chen A, Guinan E, Vogelsang G, Krishnan A, Giralt S, Revta C, Carreau NA, Iacobelli M, Carreras E, Ruutu T, Barbui T, Antin JH, Niederwieser D (2010) Hepatic veno-occlusive disease following stem cell transplantation: incidence, clinical course, and outcome. Biol Blood Marrow Transplant 16(2):157-168. doi:10.1016/j.bbmt. 2009.08.024

19. Elting LS, Cooksley C, Chambers M, Cantor SB, Manzullo E, Rubenstein EB (2003) The burdens of cancer therapy. Clinical and economic outcomes of chemotherapy-induced mucositis. Cancer 98(7):1531-1539. doi:10.1002/cncr.11671

20. Banz K, Bischoff H, Brunner M, Chouaid C, de Castro Carpeno J, de Marinis F, Grossi F, Vergnenegre A, Walzer S (2011) Comparison of treatment costs of grade $3 / 4$ adverse events associated with erlotinib or pemetrexed maintenance therapy for patients with advanced non-smallcell lung cancer (NSCLC) in Germany, France, Italy, and Spain. Lung Cancer 74(3):529-534. doi:10.1016/j.lungcan.2011.04.010

21. Moerer O, Schmid A, Hofmann M, Herklotz A, Reinhart K, Werdan K, Schneider H, Burchardi H (2002) Direct costs of severe sepsis in three German intensive care units based on retrospective electronic patient record analysis of resource use. Intensive Care Med 28(10): 1440-1446. doi:10.1007/s00134-002-1429-9

22. Paessens BJ, von Schilling C, Berger K, Shlaen M, Muller-Thomas C, Bernard R, Peschel C, Ihbe-Heffinger A (2011) Health resource consumption and costs attributable to chemotherapy-induced toxicity in German routine hospital care in lymphoproliferative disorder and NSCLC patients. Ann Oncol 22(10):2310-2319. doi:10.1093/ annonc/mdq759

23. Richardson PG, Soiffer RJ, Antin JH, Uno H, Jin Z, Kurtzberg J, Martin PL, Steinbach G, Murray KF, Vogelsang GB, Chen AR, Krishnan A, Kernan NA, Avigan DE, Spitzer TR, Shulman HM, Di Salvo DN, Revta C, Warren D, Momtaz P, Bradwin G, Wei LJ, Iacobelli M, McDonald GB, Guinan EC (2010) Defibrotide for the treatment of severe hepatic veno-occlusive disease and multiorgan failure after stem cell transplantation: a multicenter, randomized, dose-finding trial. Biol Blood Marrow Transplant 16(7):1005-1017. doi:10.1016/j.bbmt.2010.02.009
24. NUB Antrag 2012/2013 Defibrotide i.v. http://www. kinderkrebsinfode/sites/kinderkrebsinfo/content/e2260/e5888/ e84884/e84885/e113489/2013_GPOH_Defibrotide04102012 gerpdf. Accessed 29 Jan 2014

25. Lauer-Fischer Lauer-Taxe ${ }^{\circledR}$ (2013) http://www.2lauer-fischer.de/ produkte/arzneimitteldaten-online/webapo-infosystem/. Accessed 01 Mar 2014

26. Dignan FL, Wynn RF, Hadzic N, Karani J, Quaglia A, Pagliuca A, Veys P, Potter MN (2013) BCSH/BSBMT guideline: diagnosis and management of veno-occlusive disease (sinusoidal obstruction syndrome) following haematopoietic stem cell transplantation. Br J Haematol 163(4):444-457. doi:10.1111/bjh.12558

27. Graf von der Schulenburg JM, Greiner W, Jost F, Klusen N, Kubin M, Leidl R, Mittendorf T, Rebscher H, Schoeffski O, Vauth C, Volmer T, Wahler S, Wasem J, Weber C (2008) German recommendations on health economic evaluation: third and updated version of the Hanover Consensus. Value Health 11(4):539-544. doi:10.1111/j. 1524-4733.2007.00301.x

28. Centre for Evidence-Based Medicine: Number Needed to Treat (NNT). http://www.cebmnet/number-needed-to-treat-nnt/. Accessed Sep 182014

29. Lee SJ, Klar N, Weeks JC, Antin JH (2000) Predicting costs of stemcell transplantation. J Clin Oncol 18(1):64-71

30. Esperou H, Myon E, Robin M, Chadelat C, Ferry C, Devergie A, Ribaud P, Rocha V, Socié G, Gluckman E Cost-assessment of conditioning regiment in allogeneic haematopoetic stem cell transplantation using IV busulfan (Busilvex) versus oral busulfan: a French model; 31st Annual Meeting of the European Group for Blood and Marrow Transplantation 2005. http://registration.akm.ch/ einsichtphp?XNABSTRACT ID $=5305 \&$ XNSPRACHE_ID $=$ $2 \& X N K O N G R E S S \_I D=12 \& X \bar{N} M A S K E N \_I D=900$. Accessed 24 Feb 2014

31. Tellez Giron G, Salgado JL, Soto H (2012) Cost effectiveness analysis of busulfan-cyclophosphamide (BuCy2) as conditioning regimen before allogeneic human stem cell transplantation (HSCT): comparison of oral versus IV busulfan. Value Health 15(4):A220

32. Barr RD (2012) Economic evaluation of hematopoietic stem cell transplantation. Hematology 17(Suppl 1):S198-S201. doi:10.1179/ $102453312 X 13336169157176$

33. Zhang H, Graiser M, Hutcherson DA, Dada MO, McMillan S, Ali Z, Flowers CR, Waller EK (2012) Pharmacokinetic-directed high-dose busulfan combined with cyclophosphamide and etoposide results in predictable drug levels and durable long-term survival in lymphoma patients undergoing autologous stem cell transplantation. Biol Blood Marrow Transplant 18(8):1287-1294. doi:10.1016/j.bbmt.2012.02. 006

34. Lim ZY, Thanigaikumar M, Gandhi S, Pearce L, Kenyon M, Ho AYL, Devereux S, Pagliuca A, Mufti GJ (2007) Use of intravenous busulphan for reduced intensity conditioning (RIC) haematopoietic stem cell transplantation (HSCT) is associated with delayed T-cell full donor chimerism and lower incidence of acute graft versus host disease. Blood (ASH Annual Meeting Abstracts) 110 (Abstract 1994)

35. Pavletic SZ, Fowler DH (2012) Are we making progress in GVHD prophylaxis and treatment? Hematol Am Soc Hematol Educ Program 2012:251-264. doi:10.1182/asheducation-2012.1.251 